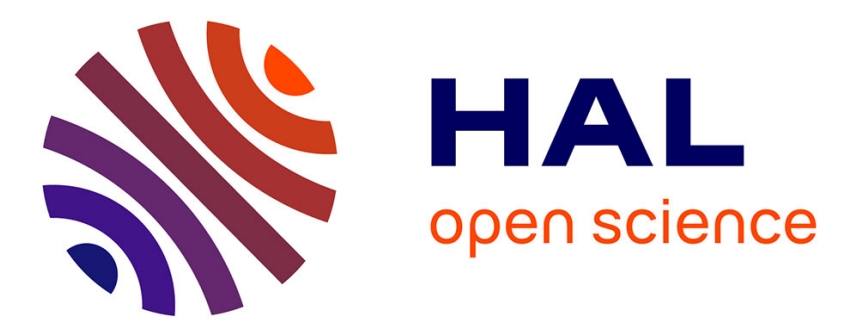

\title{
X-ray pixel detector for crystallography
}

P. Delpierre, J.F. Berar, L. Blanquart, B. Caillot, J.C. Clemens, C. Mouget

\section{To cite this version:}

P. Delpierre, J.F. Berar, L. Blanquart, B. Caillot, J.C. Clemens, et al.. X-ray pixel detector for crystallography. IEEE Transactions on Nuclear Science, 2001, 48, pp.987-991. in2p3-00013844

HAL Id: in2p3-00013844

https://hal.in2p3.fr/in2p3-00013844

Submitted on 18 Jul 2003

HAL is a multi-disciplinary open access archive for the deposit and dissemination of scientific research documents, whether they are published or not. The documents may come from teaching and research institutions in France or abroad, or from public or private research centers.
L'archive ouverte pluridisciplinaire HAL, est destinée au dépôt et à la diffusion de documents scientifiques de niveau recherche, publiés ou non, émanant des établissements d'enseignement et de recherche français ou étrangers, des laboratoires publics ou privés. 


\title{
X-Ray Pixel Detector for Crystallography
}

\author{
P. Delpierre, J.F. Berar, L. Blanquart, B. Caillot, \\ J.C. Clemens, C. Mouget
}

\begin{abstract}
For X-rays diffraction experiments, the required dynamic range is a challenge. The signal ranges usually over more than six orders of magnitude. To meet this requirement and to reduce the readout time with respect to the commonly used CCD camera a dedicated hybrid pixel detector is under development. We have designed a new counting chip with pixel sizes of $330 \mu \mathrm{m}$. The expected counting rate per pixel is $10^{7} \mathrm{ph} / \mathrm{s}$ and a continuous readout with time stamping will allow a dynamic range for up to $4 \times 10^{9}$ (16-bit counter in each pixel and 16-bit counter per pixel in the readout boards). This chip has been submitted for fabrication and it is under test. First results of this chip will be presented. As a first step a small detector (4x $1.6 \mathrm{~cm}^{2}$ ) is being built, using a DELPHI (LEP/CERN) silicon array of diodes which have good efficiency for collecting X-ray between 5 and $25 \mathrm{keV}$. After the electrical tests, the performances of this $X$-ray detector will be measured in the ESRF-D2AM beam line (Grenoble, France), scheduled in next December. If this prototype performs as expected, a large array $\left(25 \times 25 \mathrm{~cm}^{2}\right.$ ) of such detectors could be built.
\end{abstract}

\section{INTRODUCTION}

A pixel detector for X-ray crystallography is under development for the D2AM line of the ESRF X-ray synchrotron (Grenoble, France). The goal is a detector of 25 x $25 \mathrm{~cm}^{2}$ with a very high photon rate capability $\left(10^{7} \mathrm{ph} / \mathrm{s}\right.$ per pixel), a large dynamic range (more than $10^{9}$ ) and a fast image readout ( $3 \mathrm{~ms}$ /image). We first summarize the special features of X-rays detectors compared to the HEP experiments and the advantages/disadvantages of pixels versus the CCD. Then we describe the prototype under construction and the first results of the electronic chip. Finally, we will give the concept of the final project.

Manuscrpt received in November 7, 2000.

P. Delpierre is with the CPPM/IN2P3/CNRS, 163 Av. de Luminy, case 907, F-13288 Marseille Cedex 9, France (telephone: +33 4918272 00, email: delpierre@cppm.in2p3.fr).

J. F. Berar is with the Laboratoire de Crytallographie/CNRS, BP 166, F38042 Grenoble Cedex 09, France, (telephone: +33 4768874 14, e-mail: berar@esrf.fr).

L. Blanquart is with the CPPM/IN2P3/CNRS, 163 Av. de Luminy, case 907, F-13288 Marseille Cedex 9, France (telephone: +33 4918272 43, email: blanquart@cppm.in2p3.fr).

B. Caillot in with the Laboratoire de Crytallographie/CNRS, BP 166, F38042 Grenoble Cedex 09, France, (telephone: +33 4768874 14, e-mail: caillot@esrf.fr).

J. C. Clemens is with the CPPM/IN2P3/CNRS, 163 Av. de Luminy, case 907, F-13288 Marseille Cedex 9, France (telephone: +33 4918272 90, email: clemens@cppm.in2p3.fr).

C. Mouget is with the Laboratoire de Crytallographie/CNRS, BP 166, F38042 Grenoble Cedex 09, France, (telephone: +33 4768810 43, e-mail: mouget@labs.polycnrs-gre.fr).

\section{X-RAY IMAGING}

In HEP experiments we have a very large number of pixels (hundreds of millions) but a small number of hit pixels (few hundreds), in this case a sparse data readout is mandatory. In x-rays imaging more than $50 \%$ of the pixels are hit, then the sparse readout is useless. In HEP we have few hits per image and a large image readout rate. On the contrary, in X-rays imaging, we have a very large number of hits per image and, therefore, a not so fast image readout rate. The main specification for HEP is a fast sparse readout while for x-rays it is the photon counting at high rate and large dynamic range. The conclusion is that the electronic chips are not the same for HEP experiments and for the x-rays imaging.

The CCD's are used widely in x-rays imaging. However, the photon pulses are integrated and the dynamic range limits them. The pixels can solve this problem because they have a very low electronic noise and we can make photon counting with almost no fake count (less than $10^{-6}$ ). If we do that, and if we can read continuously during the data acquisition, we can have an unlimited dynamic range. Another advantage of photon counting is the ability to suppress low energy parasitic photons by a correct setting of the threshold. In general, in pixel detectors, the electronics can be adapted to the application and the chip can include a smart readout. For example the chip that we are building includes the possibility to adjust, by software, the readout rate of each pixel (individually), according to a map of average input photon flux per pixel.

As an example of the interest for the large dynamic range, the Fig. 1 represents a Bragg diffraction image [1,2]. If the dynamic range is not large enough, we cannot distinguish any structure at low intensity. This can be improved using a filter, to reduce the intensity for the main Bragg line but this artifact is not necessary with large dynamic range.

\section{THE PROTOTYPE}

To study the feasibility of the D2AM x-rays detector, we are building a prototype. The size of the pixels must agree with X-ray optic properties, that is about $0.2 \times 0.2 \mathrm{~mm}^{2}$ (ESRF source image).

To save time and money we want to use the spare sensors fabricated for the DELPHI (LEP, CERN) pixel detector [3] (see Fig. 2). However, we do not want to produce two 
different sizes of chip, then we will use only the rectangular part. The pixel size is $330 \times 330 \mu \mathrm{m}^{2}$.

We have designed an electronic chip, the XPAD, according to the requirements of the D2AM beam line. For this first prototype, the chip [4] was submitted in a standard non radiation tolerant technology. The main characteristics of this chip are the following:

- Photon counting, noise $<1$ fake hit/ $10^{6}$ event

- Maximum counting rate $: 10^{7} \mathrm{ph} / \mathrm{sec}$ per pixel

- Adjustable/tunable threshold

- Continuous counting during exposure

- Pixel by pixel tuneable readout. During data taking, one can read one count $/ \mathrm{N}, \mathrm{N}$ depending of the intensity in a given region of the picture.

- Full dynamic range (i.e. $4 \times 10^{9} \mathrm{ph}+/-1 \mathrm{ph}$ ) at the end of exposure.

The chip has been submitted in March 2000 and we received it back recently. Preliminary test results show that the chip behaves as expected. The minimum threshold is around $1000 \mathrm{e}^{-}$(see Fig. 3.). The noise is $115 \mathrm{e}^{-}$without the sensor. To estimate what would be the noise with the bumpbonded sensor, a test chip has the ability to add increasing input capacitors. For the expected capacitance of our sensor pixels (around $350 \mathrm{fF}$ ), the noise is $175 \mathrm{e}^{-}$(see Fig. 4.).

The most important characteristic of this chip is the very high counting rate. On Fig. 5., one can see that with the specified rate of $10^{7} \mathrm{ph} / \mathrm{sec}$, the observed signal is still very nice, even with an input capacitance of $400 \mathrm{fF}$.

A 16-bit counter in each pixel and another 16-bit counter per pixel in an external readout board will provide the large dynamics. The external readout board has also been designed and is being produced.

Ten of these chips have been bump-bonded on the rectangular part of the DELPHI sensors. We have built several such modules. On the Fig. 6., one can see one of the modules on which we have placed a radioactive source $\left(\mathrm{S}_{\mathrm{r}}{ }^{90}\right)$ between four chips, against the sensor. One can clearly see the beam profile. Between the chips, the pixels are larger to save the dead area. The cross in the middle of the beam is due to these larger pixels. We will then make diffraction pictures in the D2AM line to test the performance in a real $\mathrm{x}$-ray diffraction experiment.

The DELPHI sensor is a silicon wafer of about $300 \mu \mathrm{m}$ thickness. We therefore expect a good efficiency $(>50 \%)$ for photon conversion between 5 and $15 \mathrm{keV}$. To increase the efficiency for higher energy we will bump some single chips on CdTe.

\section{THE D2AM/ESRF PROJECT}

If the results of the prototypes are positive, we will propose a large pixel detector.

This detector will have the following specifications:

- Active area: $25 \times 25 \mathrm{~cm}^{2}$
- Pixel size $200 \times 200 \mu \mathrm{m}^{2}$ (or $150 \times 150 \mu \mathrm{m}^{2}$ if necessary)

- Hybrid technique: modules of $8 \times 1.6 \mathrm{~cm}^{2} \mathrm{Si}$ or CdTe detector substrate

- $\quad$ Threshold tuning (from 1200 electrons)

- Dynamic range $>10^{9}(40 \mathrm{MHz}$ continuous readout during exposure)

- Calibration pulse

- Mask, pixel by pixel

- Very low noise: less than $10^{-6}$ random hits (after masking of noisy pixels)

We will build chips based on the XPAD but with smaller pixel size. Depending on the application, the level of radiation could be several $\mathrm{kGy} / \mathrm{year}$ and this chip will be produced in a sub-micronic radiation hard process. The module will include a line of 8 chips of $16 \times 8 \mathrm{~mm}^{2}$ active surface on one $64 \times 16 \mathrm{~mm}^{2}$ sensor of $\mathrm{Si}$ or CdTe substrate (see the Fig. 7.). Then we will assemble the modules as tiles with an overlap to cover the dead surfaces (see Fig.8.).

As for the prototype, there will be a 16-bit counter in each pixel and another 16-bit counter in the readout boards. The readout will be continuous during exposure and only $3 \mathrm{~ms}$ will be necessary to complete the full $1 \mathrm{ph} / 10^{9}$ dynamics. The storage memory will be 128 images. The image readout rate to the external world will be $30 \mathrm{image} / \mathrm{s}$ at $1 \mathrm{~Gb} / \mathrm{s}$.

\section{CONCLUSION}

We are building an X-ray detector well adapted to the crystallography experiment. The electronic chip of the prototype is under test and the first results satisfy the specifications. At a pulse rate of $10^{7}$, the amplifier output reproduce very well the input charge. We are studying a large $\mathrm{x}$-ray pixel detector based on this prototype.

\section{REFERENCES}

[1] A. Letoublon, "Diffusion diffuse et phasons dans les phases icosaedriques et icosaedriques modulees Al-Pd-Mn," thesis, 20 January 2000, INPG - Grenoble.

[2] J.F. Berar, Pixel detector workshop, ESRF, Grenoble, 17 June 1999.

[3] K.H. Becks, P.Borghi, J.M. Brunet, M. Caccia, J.C. Clemens, M. Cohen-Solal, et al.., "The DELPHI PIXELS," Nucl. Instr. Meth., vol. A386, pp. 11-17, 1997.

[4] L. Blanquart, I. Valin, C. Trouilleau, S. Meillere and L. Crest, "XPAd, a New Read-out Pixel Chip for X-ray Counting," presented at the 2000 IEEE Nuclear Science Symposium, Lyon, France. 


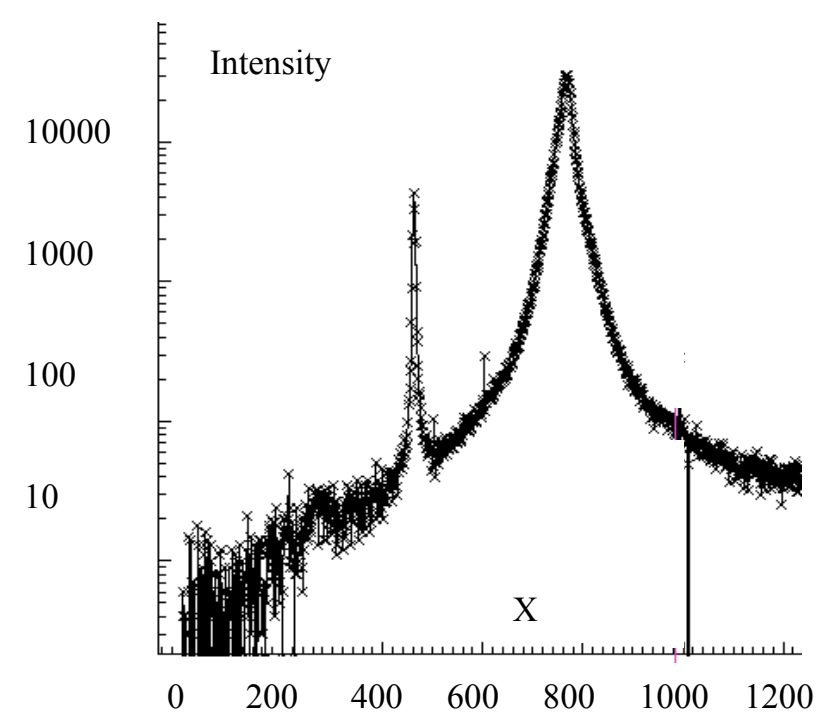

Fig. 1. CCD Bragg diffraction image.

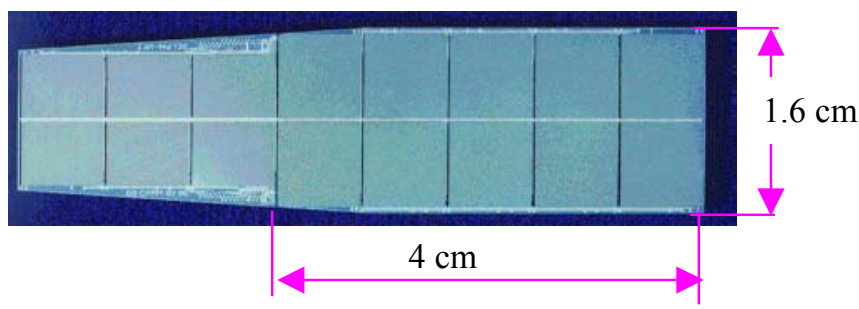

Fig. 2. DELPHI pixel detector

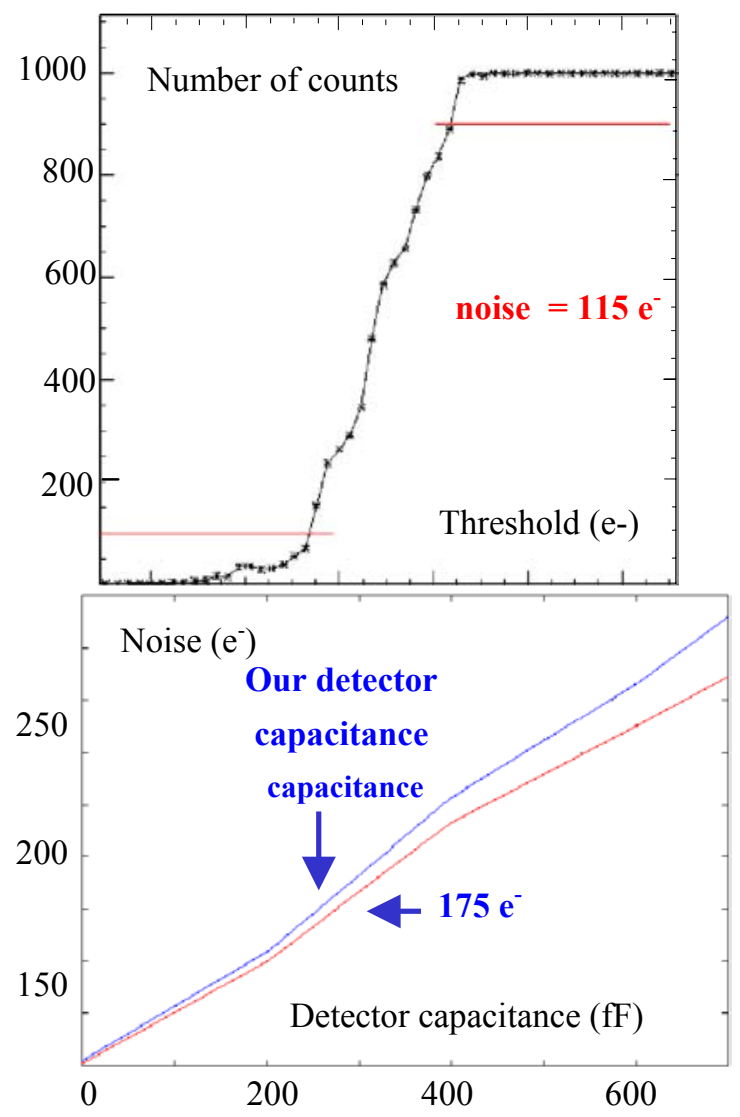

Fig. 3. Threshold curve

Fig. 4. Noise versus input capacitance

Pulse high (arbitrary units)

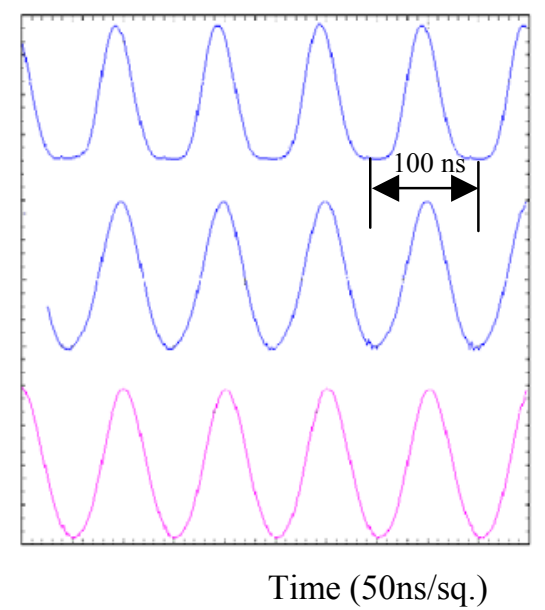

$400 \mathrm{fF}$

$700 \mathrm{fF}$

Fig. 5. Amplifier output with $10^{7}$ pulse/sec, for three input capacitance's. 


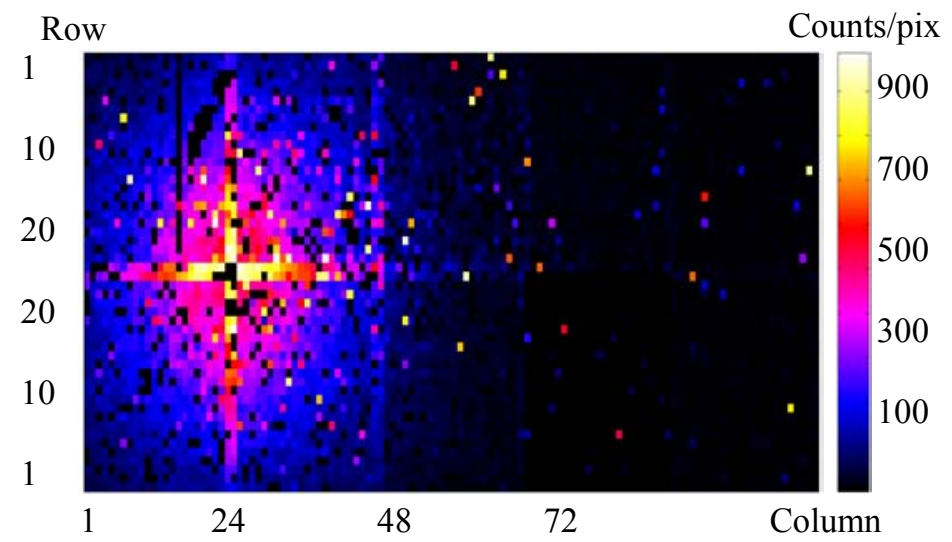

Fig. 6. Beam profile of a $\mathrm{S}_{\mathrm{r}}{ }^{90}$ source placed on a module prototype, in the middle of 4 chips (the cross is due to the larger pixels in this area)

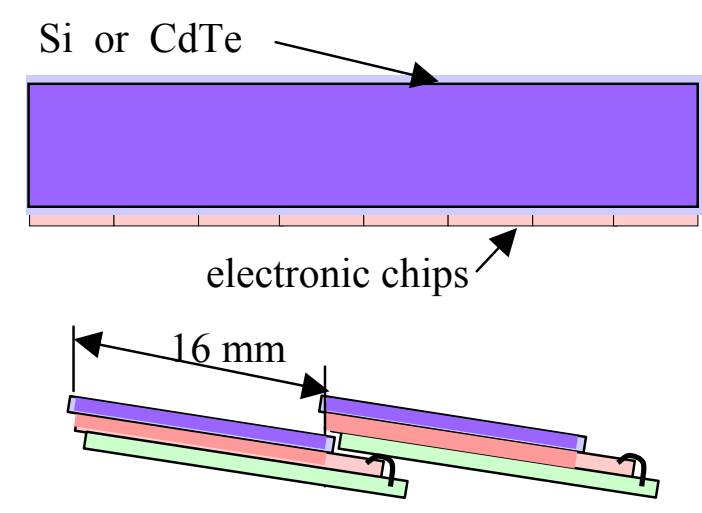

Figure 7: Modules

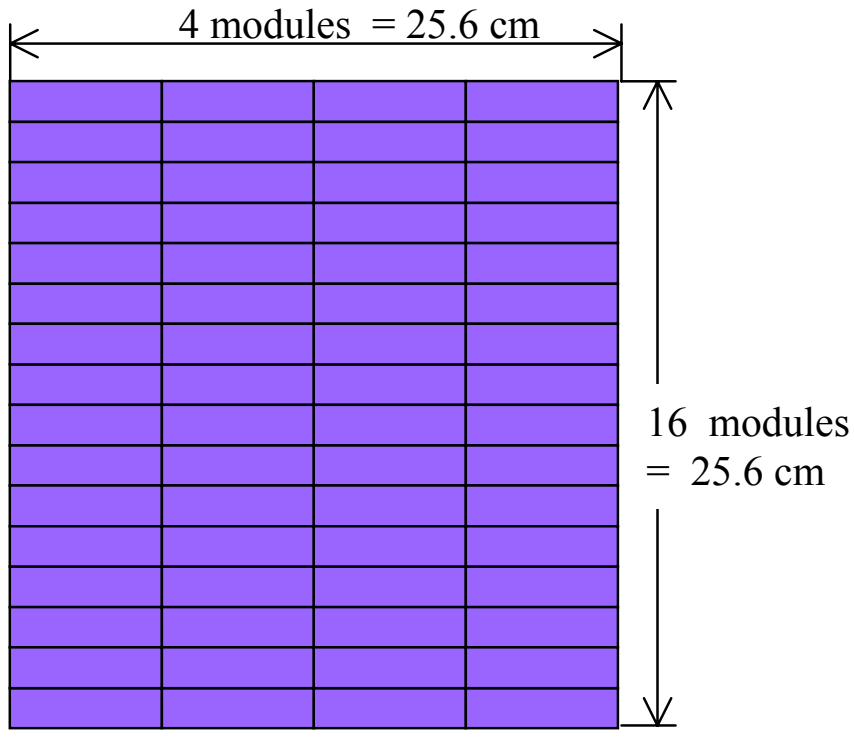

Fig. 8. Module assembly 